\title{
EVALUASI \\ SISTEM INFORMASI AKADEMIK MENGGUNAKAN METODE MCCALL
}

\author{
Surya Ade Saputera ${ }^{1}$, Dandi Sunardi ${ }^{2}$ Agusdi Syafrizal ${ }^{3}$, Pantra Samsidi $^{4}$ \\ 1,2,3 Program Studi Teknik Informatika Universitas Muhammadiyah Bengkulu \\ ${ }^{4}$ Program Studi Sistem Informasi Universitas Muhammadiyah Bengkulu \\ Jl. Bali Po. Box. 118 Kota Bengkulu

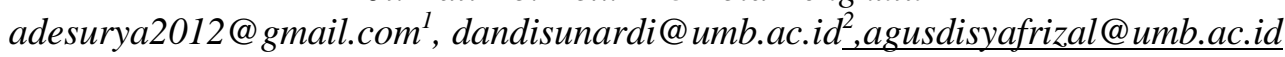

\begin{abstract}
ABSRACT - The quality of the website for higher education is very important as a medium for conveying information, universities that utilize information systems in every campus activity. After measuring the software, it will be known whether the quality of the system is good or bad. McCall's method is a method that measures software quality. McCall's factors related to the operational characteristics of the software are: correctness, reliability, efficiency, integrity, usability. In this study, measuring the quality of the Academic Information System (SIAKAD) website. Data collection methods used in this study are: Observation, questionnaire. Methods of data analysis, carried out by quantitative data analysis using measurement techniques according to the McCall method. The results of the evaluation of the quality of the Academic Information System (SIAKAD) website using the McCall method can be concluded that the Correctness and Usability quality factors are presented quite well so that it needs serious attention from the UPT ICT department, while the quality factors are reliability, Efficiency and Integrity are presented well, the quality of SIAKAD needs to be maintained well.
\end{abstract}

Keywords: Quality, Academic Information Systems, McCall

ABSTRAK - Kualitas website bagi perguruan tinggi sangat penting untuk sebagai media untuk menyampaikan informasi, perguruan tinggi yang memanfaatkan sistem informasi dalam setiap aktivitas kampus. Pengukuran perangkat lunak akan diketahui setelah dilakukannya pengukuran, apakah kualitas sistem tersebut termasuk kategori baik atau buruk. Metode McCall merupakan metode yang mengukur kualitas perangkat lunak. Faktor-faktor McCall yang berkaitan dengan sifat-sifat operasional perangkat lunak adalah: correctness, reliability, efficiency, integrity, usability. Pada penelitian ini mengukur kualitas website Sistem Informasi Akademik (SIAKAD). Metode pengumpulan data yang dilakukan dalam penelitian ini adalah : Observasi, Kuesioner. Metode analisis data, dilakukan dengan analisis data secara kuantitatif dengan menggunakan teknik pengukuran menurut metode McCall. Hasil evaluasi kualitas website Sistem Informasi Akademik (SIAKAD) menggunakan metode McCall dapat disimpulkan faktor kualitas Correctness dan Usability di presentasikan cukup baik sehingga perlu mendapatkan perhatian serius dari bagian UPT TIK, sedangkan faktor kualitas reliability, Efficiency dan Integrity di presentasikan baik, kualitas SIAKAD perlu dipertahankan dengan baik.

Kata kunci : Kualitas, Sistem Infomasi Akademik, McCall

\section{PENDAHUluAN}

A. Latar Belakang

Era Industri 4.0 yang di kembangkan saat ini menggabungkan Internet dengan hal-hal yang berhubungan dengan kegiatan sehari-hari masyarakat. Perkembangan teknologi jaringan internet, dapat menjadi jembatan penghubung antara satu orang dengan orang berada jauh di waktu dan tempat berbeda dengan cepat dan mudah. Untuk menghubungkan dan memudahkan komunikasi untuk itu diperlukan sebuah media seperti website.

Website salah satu dari banyaknya media dalam pemanfaatan jaringan internet. Website atau World Wide Web (WWW) adalah salah satu media penting dimana pengguna dapat menemukan semua jenis informasi yang berkaitan dengan bidang mereka sendiri merupakan salah satu bentuk media masa yang dipublikasi melalui jaringan internet yang dapat diakses dimanapun dan kapanpun. ${ }^{1}$

Sistem informasi adalah suatu sistem didalam suatu organisasi yang mempertemukan kebutuhan pengelolaan transaksi harian, mendukung operasi, bersifat manajerial, dan kegiatan strategi dari suatu organisasi dan menyediakan pihak luar tertentu dengan laporan - laporan yang dibutuhkan. ${ }^{2}$

Sebuah website selain harus memenuhi faktorfaktor kualitas yang harus dimiliki oleh software juga harus memenuhi faktor-faktor kualitas dari sisi desain maupun konten. ${ }^{3}$ Website yang baik adalah situs web yang banyak diminati oleh penggunanya. ${ }^{4}$ Kualitas website berserta keunggulannya, khususnya bagi perguruan tinggi sangat penting untuk sebagai media untuk menyampaikan informasi, perguruan tinggi yang memanfaatkan 
sistem informasi dalam setiap aktivitas kampus tentu memberikan dampak pada peningkatan mutu dan pelayanan perguruan tinggi tersebut.

Dengan pemanfaatan website pelayanan akademik yang diberikan perguruan tinggi menjadi lebih mudah dan efisien. Mahasiswa mampu mengakses Sistem informasi Akademik kapan pun dan dimana pun berada. Maka diperlukan kualitas website Sistem Informasi Akademik yang lebih baik untuk memberikan pelayanan kepada mahasiswa.

Universitas Muhammadiyah Bengkulu sebagai salah satu perguruan tinggi terbaik di kota Bengkulu, dalam memberikan pelayanan kepada mahasiswa UMB menggunakan website sistem infomasi akademik untuk memudahkan mahasiswa dalam mendapatkan informasi akademik, seperti biodata mahasiswa, pengisian KRS, informasi dosen, informasi kelas perkuliahan, informasi biaya dan tagihan keuangan serta informasi hasil studi mahasiswa. Aktivitas website sistem informasi akademik setiap harinya meningkat,dilihat dari banyaknya pengunjung website pada waktu - waktu pengisian Kartu rencana Studi.

Dengan banyaknya mahasiswa yang mengakses sistem informasi akademik kinerja dari website perlu ditingkatkan, tampilan website yang tidak mudah digunakan oleh mahasiswa membingungkan mahasiswa dalam mengakses website sistem informasi akademik, dari sisi konten juga dapat menjadi masalah apabila konten yang diperlukan mahasiswa tidak sesuai dengan yang mereka dapatkan, misalnya terjadi kesalahan kelas perkuliahan yang dipilih dengan dosen dan matakuliahnya, kelas perkuliahan yang penuh sehingga mahasiswa tidak dapat memilih kelas perkuliahan tersebut, terjadi perubahan KRS yang diambil padahal mahasiswa sudah menentukan KRS, Informasi transaksi biaya kuliah yang tidak sesuai dengan yang sudah dibayarkan dengan permasalahan tersebut maka diperlukan kualitas website yang baik yang menunjang pelayanan akademik kepada mahasiswa, diperlukan penelitian yang mengevaluasi kualitas website sistem informasi akademik Universitas Muhammadiyah Bengkulu.

Evaluasi perangkat lunak menjadi penting karena hasil evaluasi kualitas sistem akan diketahui setelah dilakukannya pengukuran, apakah kualitas sistem tersebut termasuk kategori baik atau buruk atau sudah sesuai dengan harapan pengguna terhadap sistem yang digunakan. Salah satu metode evaluasi adalah dengan pengujian berdasarkan teori kualitas $\mathrm{McCall} .^{7}$

Metode McCall merupakan metode yang mengukur atau mengevaluasi kualitas perangkat lunak yang menggabungkan 11 faktor dari Product Operation (Correctness, Reliability, Efficiency, Integirity,Usability,) , Product Revision (Maintainability, Flexibility, Testability), dan Product Transtition (Portability, Reusability,
Interoperability). Ide utama McCall adalah untuk menilai hubungan factor-faktor kualitas dan kriteria kualitas produk atau meningkatkan kualitas perangkat lunak ${ }^{5}$.

Evaluasi kualitas suatu sistem informasi sangatlah penting dilakukan untuk mengetahui bagaimana kondisi terkini dari sistem informasi itu sendiri, apakah masih relevan ataukah tidak dengan kondisi terkini, apabila setelah dilakukan pengukuran ternyata sistem informasi tersebut sudah tidak relevan maka dapat dijadikan acuan ataupun rujukan untuk diadakan perbaikan agar lebih baik lagi. ${ }^{7}$

\section{TINJAUAN PUSTAKA}

\section{A. Sistem Informasi}

Sistem informasi adalah suatu sistem didalam suatu organisasi yang mempertemukan kebutuhan pengelolaan transaksi harian, mendukung operasi, bersifat manajerial, dan kegiatan strategi dari suatu organisasi dan menyediakan pihak luar tertentu dengan laporan - laporan yang dibutuhkan. ${ }^{2}$ Sistem informasi adalah suatu sistem didalam suatu organisasi yang mempertemukan kebutuhan pengolahan transaksi harian, mendukung operasi ,bersifat manajerial dan kegiatan strategi dari suatu organisasi dan menyediakan pihak luar tertentu dengan laporan-laporan yang diperlukan ${ }^{6}$.

Sistem informasi adalah suatu sistem di dalam suatu organisasi yang mempertemukan kebutuhan pengolahan transaksi harian yang mendukung fungsi operasi organisasi yang bersifat manajerial dengan kegiatan strategi dari suatu organisasi untuk dapat menyediakan kepada pihak luar tertentu dengan laporan-laporan yang diperlukan. ${ }^{7}$ Manfaat adanya sistem informasi dalam suatu instansi yaitu: Menyajikan informasi guna mendukung pengambilan suatu keputusan, Menyajikan informasi guna mendukung operasi harian. Menyajikan informasi yang berkenaan dengan kepengurusan.

\section{B. Sistem Informasi Akademik}

Sistem Informasi Akademik merupakan suatu system informasi yang terdapat pada instansi pendidikan, system informasi akademik meliputi pengambilan mata kuliah, akumulasi kredit semester, pengolahan nilai, dan penentuan pembimbing akademik.System informasi akademik pada Universitas Boyolali mempunyai peran dalam mengolah suatu data menjadi informasi yang digunakan oleh mahasiswa dan dosen. Dan bagian Akademik akan lebih mudah dalam mengolah datadata mahasiswa dengan memanfaatkan kecanggihan teknologi. ${ }^{8}$

\section{Evaluasi}

Evaluasi merupakan bagian dari sistem manajemen yaitu perencanaan, organisasi, 
pelaksanaan, monitoring dan evaluasi. Evaluasi sistem informasi dapat dilakukan dengan cara berbeda dan pada tingkatan berbeda, tergantung pada tujuan evaluasinya. Tujuannya adalah untuk menilai kemampuan teknis, pelaksanaan operasional, dan pendayagunaan sistem. Evaluasi dilakukan untuk mendefinisikan seberapa baik sistem berjalan. ${ }^{12}$ Tujuan evaluasi sistem informasi antara lain : menilai kemampuan teknis dari sebuah sistem informasi. Dan menilai keberhasilan dan kegagalan pelaksanaan operasional sistem informasi ${ }^{13}$

\section{Kualitas}

Kualitas website dipengaruhi tiga hal yaitu kulitas system (system quality), kualitas layanan(service quality) dan kualitas informasi (information quality). Sebuah system baik memungkinkan pengguna untuk menggunakan website untuk memecahkan masalah mereka. Kualitas pelayanan yang baik dapat membantu pengguna mendapatkan kekuatan penuh dari website dengan cara mencocokan dengan harapan mereka. Kualitas informasi menunjukkan sejauh mana isi dari website tersebut tepat waktu (up date), akurat, dan lengkap. ${ }^{14}$

\section{E. McCall}

Jim McCall dan rekan-rekannya pada tahun 1977 telah mengusulkan suatu penggolongan faktorfaktor atau kriteria yang mempengaruhi kualitas perangkat lunak. McCall mencoba untuk menjembatani antara pengguna dan pengembang dengan berfokus pada sejumlah faktor kualitas perangkat lunak yang mencerminkan pandangan pengguna dan prioritas pengembang. ${ }^{9}$ Tujuannya adalah untuk meningkatkan kualitas produk perangkat lunak.

McCall membagi faktor-faktor tersebut menjadi tiga aspek penting yang saling berkaitan, yaitu: Operasional Produk (product Operation), Revisi Produk (Product Revision), dan Transisi Produk (product Transition). Product Operation : Correctness Reliability Usability Integrity Efficiency, Product Transition : Portability Reusability Interoperability dan Product Revision : Maintanability Flexibility Testability. Sifat-sifat operasional dari perangkat lunak harus menjadi sorotan utama yang wajib diperhatikan oleh para perancang dan pengembang aplikasi perangkat lunak karena yang menjadi ukuran adalah yang berhubungan dengan teknis analisa perancangan, dan kontruksi perangkat lunak.

Faktor-faktor McCall yang berkaitan dengan sifat-sifat operasional perangkat lunak adalah:

a) Kebenaran(correctness)-Tingkat dimana program memenuhi spesifikasinya dan memenuhi sasaran misi pelangan.

b) Keandalan (reliability)-Tingkat dimana sebuah program dapat melakukan fungsi tertentu sesuai dengan yang diharapkan dengan tingkat ketelitian yang diminta.

c) Efisiensi(efficiency)-Jumlah sumber daya komputasi dan kode yang diperlukan program untuk melaksanakan fungsinya secara baik dan benar.

d) Integritas (integrity)-Tingkat dimana akses ke perangkat lunak atau data oleh orang yang tidak berhak dapat dikontrol.

e) Penggunaan(usability)-Besarnya usaha yang diperlukan untuk mempelajari, mengoperasikan, menyediakan asupan (input), dan menafsirkan luaran (output) untuk suatu program.

Pada penelitian ini menggunakan faktor operasional dalam mengukur kualitas website sistem informasi akademik universitas muhammadiyah bengkulu.Sebuah set metrik didefinisikan dan digunakan untuk mengembangkan ekspresi untuk masing-masing faktor sesuai dengan hubungan berikut :

$\mathrm{Fq}=c_{1} * m_{1}+c_{2} * m_{2}+\ldots+C_{n} * m_{n}$

Menurut Richardus Eko Indrajit, dimana :

$\mathrm{Fq}=$ Faktor Software Quality

$\mathrm{c}_{1}=$ Bobot yang tergantung pada produk dan kepentingan

$\mathrm{m} 1$ = Metric yang mempengaruhi faktor software quality ${ }^{10}$

\section{METODOLOGI PENELITIAN}

A. Metode Pengumpulan Data

Metode pengumpulan data yang dilakukan dalam penelitian ini adalah :

1. Observasi

Melakukan dengan mengakses langsung di laman SIAKAD UMB.

2. Kuesioner

Menyebarkan kuesioner kepada pengguna Sistem Informasi Akademik UMB, dalam penelitian ini diambil sampel pengguna dari bagian UPT TIK sebagai pihak yang mengelola sistem SIAKAD UMB, Mahasiswa dan Dosen sebagai pihak yang menggunakan SIAKAD UMB. Kuesioner yang dibagikan adakah kuesioner dengan faktor Correctness dan Usability.

B. Metode Analisis Data

Dilakukan dengan analisis data secara kuantitatif dengan menggunakan teknik pengukuran menurut metode McCall.

Langkah - langkah penilaian menggunakan metode McCall :

a. faktor kualitas yang ada pada metode McCall yaitu Product operation beberapa faktor yaitu correctness, reliability, usability, integrity, dan usability.

b. Menentukan kriteria yang digunakan untuk mengukur suatu faktor. 
c. Menentukan bobot (c) dari setiap kriteria (0.1 $<=\mathrm{c}<=0.4$ ), dimana $0.1=$ sangat tidak penting, $0.2=$ tidak penting, $0.3=$ penting, $0.4=$ sangat penting.

d. Menentukan skala nilai kriteria, dimana skala penilaian yang digunakan antara $1-4$, dengan ketentuan : $1=$ sangat tidak setuju, $2=$ tidak setuju, 3 = setuju, dan $4=$ sangat setuju.

e. Memasukan nilai pada tiap kriteria hasip penilaian responden.

f. Menghitung nilai total dengan rumus : $\mathrm{Fq}=$ $c_{1} * m_{1}+c_{2} * m_{2}+\ldots+C_{n} * m_{n}$, dimana $\mathrm{Fq}$ adalah nilai total dari faktor $\mathrm{q}, \mathrm{c} 1$ adalah bobot untuk kriteria 1, dan $\mathrm{m} 1$ adalah nilai untuk kriteria 1.

g. Kemudian nilai Quality factor diubah dalam bentuk persentase $(\%)$. Besarnya persentase dihitung dengan menggunakan persamaan berikut ini :

Persentase $=\frac{\text { Nilai Yang Didapat }}{\text { Nilai Maksimum }} \times 100 \%$

Hasil persentase digunakan untuk memberikan jawaban atas kelayakan dari aspek - aspek yang diteliti. Pembagian kategori kelayakan, ada lima. ${ }^{15}$

Tabel 1. Kategori Kelayakan

\begin{tabular}{|l|l|}
\hline Ketegori & Persentase \\
\hline Sangat Baik & $81 \%-100 \%$ \\
\hline Baik & $61 \%-80 \%$ \\
\hline Cukup Baik & $41 \%-60 \%$ \\
\hline Tidak baik & $21 \%-40 \%$ \\
\hline Sangat Tidak Baik & $<21 \%$ \\
\hline
\end{tabular}

\section{HASIL DAN PEMBAHASAN}

Tampilan sistem informasi akademik (SIAKAD), dapat dilihat pada gambar 1 berikut ini :

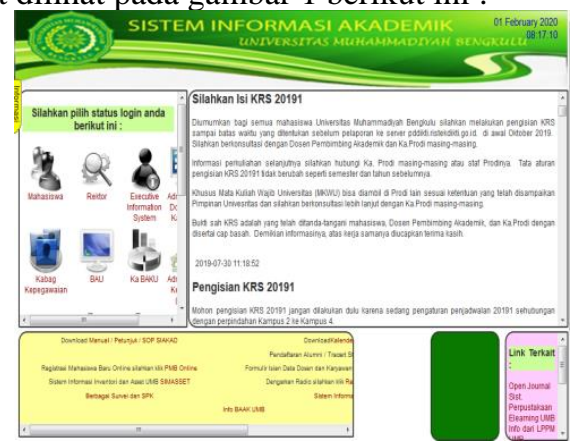

Gambar 1. Tampilan Menu Utama SIAKAD

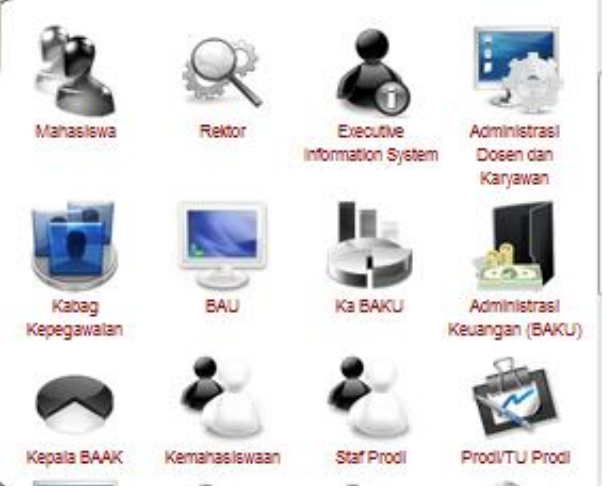

Gambar 2. Tampilan Daftar Level Akun

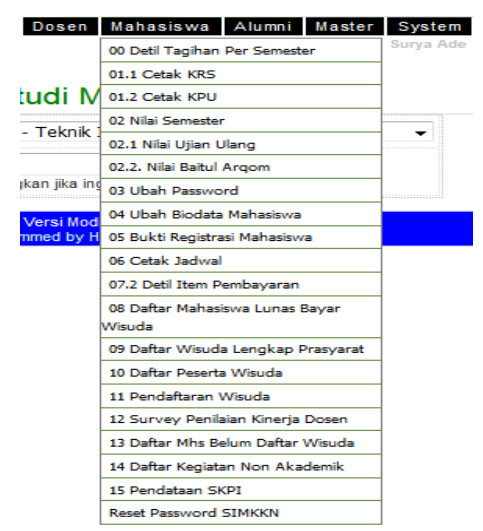

Gambar 6. Daftar Sub Menu

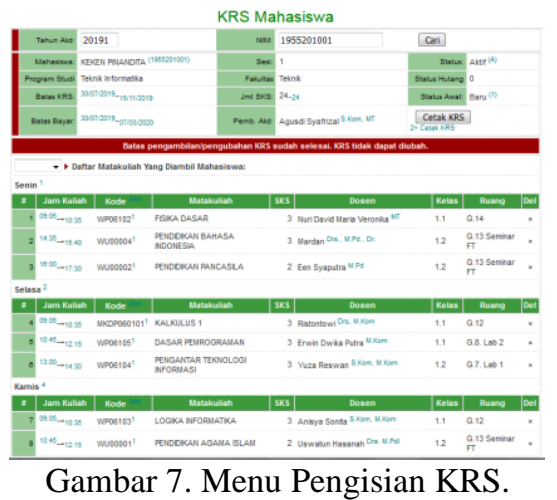

Dalam menentukan kriteria pada kuesioner dari bagian UPT TIK sebagai pihak pengelola dari SIAKAD untuk penilaian bobot pada kriteria pada faktor kualitas correctness dan Usability. Kemudian memasukan hasil penilaian dari UPT TIK kedalam bobot kriteria untuk kemudian dibagikan kepada responden untuk mendapatkan nilai dari masingmasing kriteria dari faktor kualitas correctness dan Usability

Setelah itu menentukan nilai rata-rata pada setiap faktor kualitas correctness dan Usability yang diperoleh dari 580 responden. Hasil dari penilaian responden dari masing-masing kriteria dijumlahkan dan kemudian dibagi sebanyak jumlah responden sehingga ditemukan nilai rata-rata atas masing masing faktor kualitas correctness dan Usability.

\section{A. Analisis Hasil Faktor Kualitas Correctness}

Tabel 2. Tabel Hasil Penilaian Faktor Kualitas Correctness

\begin{tabular}{|c|c|c|c|c|}
\hline $\begin{array}{l}\text { Fakto } \\
\mathrm{r} \\
\text { Kuali } \\
\text { tas }\end{array}$ & Kriteria & & $\begin{array}{l}\text { Bobo } \\
\mathrm{t} \\
\text { Krite } \\
\text { ria }\end{array}$ & $\begin{array}{l}\text { Nil } \\
\text { ai } \\
\text { Rat } \\
\text { a2 }\end{array}$ \\
\hline 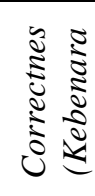 & $\begin{array}{c}\text { Completen } \\
\text { ess } \\
\text { (Kelengka } \\
\text { pan) }\end{array}$ & $\begin{array}{l}\text { SIAKAD } \\
\text { UMB } \\
\text { mampu } \\
\text { menampi } \\
\text { lkan }\end{array}$ & 0.4 & 2 \\
\hline
\end{tabular}




\begin{tabular}{|c|c|c|c|}
\hline & $\begin{array}{l}\text { informasi } \\
\text { pada } \\
\text { setiap } \\
\text { menu } \\
\text { yang } \\
\text { disediaka } \\
\text { n }\end{array}$ & & \\
\hline & $\begin{array}{l}\text { SIAKAD } \\
\text { UMB } \\
\text { mampu } \\
\text { menampi } \\
\text { lkan } \\
\text { kesesuaia } \\
\text { n } \\
\text { informasi } \\
\text { pada } \\
\text { setiap } \\
\text { menu. }\end{array}$ & 0.4 & 2 \\
\hline & $\begin{array}{l}\text { Ketersedi } \\
\text { aan } \\
\text { informasi } \\
\text { sesuai } \\
\text { yang } \\
\text { dibutuhk } \\
\text { an dan up } \\
\text { to date. }\end{array}$ & 0.4 & 1 \\
\hline & $\begin{array}{l}\text { Keseluru } \\
\text { han menu } \\
\text { dan fitur } \\
\text { dapat } \\
\text { berfungsi } \\
\text { dengan } \\
\text { baik. }\end{array}$ & 0.4 & 2 \\
\hline \multirow[t]{2}{*}{$\begin{array}{c}\text { Consisten } \\
c y \\
\text { (Konsisten } \\
\text { ) }\end{array}$} & $\begin{array}{l}\text { SIAKAD } \\
\text { UMB } \\
\text { memiliki } \\
\text { desain } \\
\text { tampilan } \\
\text { (warna, } \\
\text { jenis } \\
\text { huruf, } \\
\text { tata letak) } \\
\text { yang } \\
\text { konsisten } \\
\text { (tetap/tid } \\
\text { ak } \\
\text { berubah- } \\
\text { ubah) } \\
\text { pada } \\
\text { setiap } \\
\text { halamann } \\
\text { ya. }\end{array}$ & 0.4 & 2 \\
\hline & $\begin{array}{l}\text { Bahasa } \\
\text { yang } \\
\text { digunaka } \\
\mathrm{n} \\
\text { konsisten } \\
\text { (tetap/tid } \\
\text { ak } \\
\text { berubah- }\end{array}$ & 0.4 & 2 \\
\hline
\end{tabular}

\begin{tabular}{|c|c|c|c|}
\hline & $\begin{array}{l}\text { ubah) } \\
\text { pada } \\
\text { setiap } \\
\text { halamann } \\
\text { ya. }\end{array}$ & & \\
\hline \multirow{2}{*}{$\begin{array}{c}\text { Traceabili } \\
\text { ty } \\
\text { (Pelacaka } \\
\text { n) }\end{array}$} & $\begin{array}{l}\text { SIAKAD } \\
\text { UMB } \\
\text { mampu } \\
\text { melakuka } \\
\mathrm{n} \\
\text { pencarian } \\
\text { data atas } \\
\text { keseluruh } \\
\text { an konten } \\
\text { yang } \\
\text { terdapat } \\
\text { dalam } \\
\text { sistem. }\end{array}$ & 0.4 & 1 \\
\hline & $\begin{array}{l}\text { SIAKAD } \\
\text { UMB } \\
\text { mampu } \\
\text { melakuka } \\
\text { n } \\
\text { pelacaka } \\
\text { n } \\
\text { terhadap } \\
\text { kesalahan } \\
\text { pengguna } \\
\text { an. }\end{array}$ & 0.4 & 2 \\
\hline
\end{tabular}

Berikut perhitungan faktor kualitas Correctness :

Fcorrectness $\quad=c_{1} * m_{1}+c_{2} * m_{2}+\ldots+C_{n} * m_{n}$

$$
=
$$

$(0.4 * 2)+(0.4 * 2)+(0.4+1)+(0.4 * 2)+(0.4 * 2)+(0.4+2)$ $+(0.4 * 1)+(0.4 * 2)$

$$
\begin{aligned}
0.8+0.4+0.8 & =0.8+0.8+0.4+0.8+0.8+ \\
& =5.6 \\
\text { Persentase } & =\frac{5.6}{13} \times 100 \% \\
& =43.8 \%
\end{aligned}
$$

Berdasarkan hasil kategori kelayakan yang ditunjukan pada tabel diatas, maka dapat disimpulkan bahwa faktor kualitas correctness memiliki interprestasi Cukup Baik. Rekomendasi yang dapat diusulkan kepada pihak pengembang SIAKAD yakni UPT TIK, melakukan perbaikan atas ketersediaan informasi yang selalu terbaru atau dinamis sesuai dengan informasi yang dibutuhkan oleh pengguna SIAKAD. Usulan rekomendasi untuk SIAKAD selanjutnya kemampuan SIAKAD untuk menyelesaikan tugas pencarian data yang dibutuhkan pengguna, tidak mengalami kesulitan untuk menemukan menu yang dibutuhkan.

B. Analisis Hasil Faktor Kualitas Reliability

Untuk mengukur kualitas website SIAKAD dari faktor Reliability menggunakan tools stress testing dengan aplikasi webserver stress tool. Stress 
Testing merupakan metode evaluasi website yang dapat menentukan kehadalan suatu website dengan melakukan pengujian diluar batas penggunaan secara normal. ${ }^{5}$

Tabel 3 :

Hasil Faktor Kualitas Reliability

\begin{tabular}{|l|c|c|}
\hline Jenis Test & $\begin{array}{c}\text { Persentase } \\
\text { Error Per } \\
\text { URL }\end{array}$ & $\begin{array}{c}\text { Persentase } \\
\text { Sukses per } \\
\text { URL }\end{array}$ \\
\hline Click Test & $40,9 \%$ & $59,1 \%$ \\
\hline Time Test & $28,7 \%$ & $71,2 \%$ \\
\hline Ramp Test & $17,3 \%$ & $82,7 \%$ \\
\hline Rata-rata & $28,9 \%$ & $71 \%$ \\
\hline
\end{tabular}

Dapat dilihat dari hasil uji menggunakan aplikasi webserver stress tool, berdasarkan hasil evaluasi faktor kualitas reliability yang ditunjukan pada tabel diatas bahwa persentase kehandalan ratarata dengan menggunakan jenis test, click test, time test, dan ramp test adalah sebesar $71 \%$ maka dapat disimpulkan bahwa faktor kualitas reliability memiliki interpretasi baik. Dari hasil faktor kualitas reliability rekomendasi yang dapat dilakukan kepada SIAKAD yakni dari hasil rata-rata persentase error sebesar $28.9 \%$ maka perlu untuk dilakukan perbaikan terhadap kemampuan website SIAKAD dalam melakukan pelayanan kepada pengguna, usulan perbaikan terhadap fungsi - fungsi dari menu SIAKAD, hal ini dilakukan secara rutin agar error yang terjadi selalu dalam monitoring UPT TIK dengan harapan meningkatkan kinerja SIAKAD yang handal.

C. Analisis Hasil Faktor Efficiency

Untuk mengukur tingkat kualitas faktor kualitas efficiency menggunakan tools secara online yakni Gtmetrix. Dimana Gtmetrix adalah aplikasi berbasis web yang berguna mengetahui performa website terkait dengan efficiency dari sebuah perangkat lunak dalam memberikan kinerja yang sesuai terhadap jumlah sumber daya yang digunakan untuk mengukur kecepatan mengerjakan tugas tertentu. Adapun hasil pengukuran kualitas faktor efficiensy menggunakan Gtmetrix adalah sebagai berikut :

Tabel 4.

Hasil Evaluasi Faktor Kualitas Efficiency

\begin{tabular}{|l|c|}
\hline Jenis Test & Persentase Hasil \\
\hline PageSpeed & $73 \%$ \\
\hline Yslow & $71 \%$ \\
\hline Rata-rata & $72 \%$ \\
\hline
\end{tabular}

Berdasarkan hasil tabel 4 diatas, disimpulkan bahwa kategori Efficeincy memiliki interprestasi baik. Rekomendasi yang dapat diberikan kepada pengembang website SIAKAD yakni mempertahankan kinerja saat ini atas sumberdaya yang telah dimiliki. Performa SIAKAD yang baik memberikan kenyamanan kepada pengguna SIAKAD.

D. Analisis Hasil Faktor Integrity.

Untuk mengukur tingkat kualitas website faktor kualitas Integrity menggunakan tools secara online yakni sucuri site check yang berfungsi untuk mengukur keamanan suatu website. Adapun hasil pengukuran kualitas faktor integrity menggunakan sucuri site check adalah sebagai berikut :

Tabel 5.

Hasil Evaluasi Faktor Kualitas Integrity

\begin{tabular}{|l|c|}
\hline Jenis keamanan & $\begin{array}{l}\text { Tingkat } \\
\text { Resiko }\end{array}$ \\
\hline Malware & Rendah \\
\hline $\begin{array}{l}\text { Website } \\
\text { Blacklisting }\end{array}$ & Rendah \\
\hline Injected SPAM & Rendah \\
\hline Defacements & Rendah \\
\hline Website Firewall & Tinggi \\
\hline
\end{tabular}

Berdasarkan hasil tabel 5 diatas, disimpulkan bahwa kategori integrity bahwa untuk daya tahan website terhadap malware, website blacklisting, injected spam dan defacements memiliki resiko rendah sehingga perlu dilakukan perbaikan oleh pihak UPT TIK terhadap integritas dari Website SIAKAD. Sedangkan website firewall ditemukan resiko tinggi karena tidak ditemukan perlidungan terhadap website sehingga SIAKAD sering mengalami gangguan karena diretas oleh pihak lain maka diperlukan bantuan dari pihak ketiga untuk perlindungan firewall.

\section{E. Analisis Hasil Faktor Kualitas Usability} Tabel 6.

Tabel hasil penilaian faktor kualitas Usability

\begin{tabular}{|c|c|c|c|c|}
\hline $\begin{array}{l}\text { Fakto } \\
\mathrm{r} \\
\text { Kuali } \\
\text { tas }\end{array}$ & \multicolumn{2}{|l|}{ Kriteria } & $\begin{array}{l}\text { Bob } \\
\text { ot } \\
\text { Krit } \\
\text { eria }\end{array}$ & $\begin{array}{l}\text { Nila } \\
\text { i } \\
\text { Rat } \\
\text { a2 }\end{array}$ \\
\hline \multirow{4}{*}{ 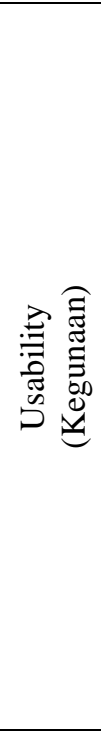 } & \multirow{4}{*}{$\begin{array}{l}\text { Operabili } \\
\text { ty } \\
\text { (Kemuda } \\
\text { han } \\
\text { mengoper } \\
\text { asikan } \\
\text { program) }\end{array}$} & $\begin{array}{l}\text { SIAKAD } \\
\text { dapat } \\
\text { dioperasikan } \\
\text { dengan mudah }\end{array}$ & 0.4 & 3 \\
\hline & & $\begin{array}{l}\text { Menu dan } \\
\text { Informasi pada } \\
\text { SIAKAD } \\
\text { dapat dipahami } \\
\text { dengan baik }\end{array}$ & 0.4 & 3 \\
\hline & & $\begin{array}{l}\text { Informasi Pada } \\
\text { SIAKAD } \\
\text { dapat } \\
\text { ditemukan } \\
\text { dengan mudah } \\
\text { dan cepat. }\end{array}$ & 0.4 & 2 \\
\hline & & $\begin{array}{l}\text { Secara } \\
\text { Keseluruhan } \\
\text { SIAKAD }\end{array}$ & 0.4 & 2 \\
\hline
\end{tabular}

43 |http://www.jurnal.umb.ac.id/index.php/JTIS 


\begin{tabular}{|c|c|c|c|}
\hline & $\begin{array}{l}\text { UMB dapat } \\
\text { memberikan } \\
\text { kepuasan dan } \\
\text { kenyamanan } \\
\text { terhadap } \\
\text { pengguna. }\end{array}$ & & \\
\hline \multirow{4}{*}{$\begin{array}{c}\text { Training } \\
\text { (Sejauh } \\
\text { mana } \\
\text { SIAKAD } \\
\text { membant } \\
\text { u } \\
\text { penggun } \\
\text { a) }\end{array}$} & $\begin{array}{l}\text { Ketersediaan } \\
\text { menu berupa } \\
\text { petunjuk/bantu } \\
\text { an/help untuk } \\
\text { membantu } \\
\text { pengguna } \\
\text { dalam } \\
\text { menggunakan } \\
\text { SIAKAD }\end{array}$ & 0.4 & 2 \\
\hline & $\begin{array}{l}\text { Informasi } \\
\text { (seperti } \\
\text { bantuan } \\
\text { online, dan } \\
\text { dokumentasi } \\
\text { lainnya) } \\
\text { tersedia } \\
\text { dengan jelas. }\end{array}$ & 0.4 & 2 \\
\hline & $\begin{array}{l}\text { Ketersediaan } \\
\text { sarana untuk } \\
\text { memberikan } \\
\text { saran, kritik } \\
\text { dan keluhan } \\
\text { kepada } \\
\text { administator }\end{array}$ & 0.4 & 3 \\
\hline & $\begin{array}{l}\text { SIAKAD } \\
\text { memberikan } \\
\text { pesan } \\
\text { kesalahan } \\
\text { sehingga } \\
\text { membantu } \\
\text { pengguna } \\
\text { memperbaiki } \\
\text { kesalahan. }\end{array}$ & 0.3 & 2 \\
\hline
\end{tabular}

Berikut perhitungan faktor kualitas Correctness :

$$
\begin{aligned}
& \text { Fcorrectness } \quad=c_{1} * m_{1}+c_{2} * m_{2}+\ldots+C_{n} * m_{n} \\
& = \\
& (0.4 * 3)+(0.4 * 3)+(0.4+2)+(0.4 * 2)+(0.4 * 2)+(0.4+2) \\
& +(0.4 * 3)+(0.3 * 2) \\
& 0.8+1.2+0.6 \\
& =1.2+1.2+0.8+0.8+0.8+ \\
& =7.4 \\
& \text { Persentase } \quad=\frac{7.4}{12} \times 100 \% \\
& =59.7 \%
\end{aligned}
$$

Berdasarkan hasil kategori kelayakan yang ditunjukan pada tabel diatas, maka dapat disimpulkan bahwa faktor kualitas Usability memiliki interprestasi Cukup Baik.

\section{Penutup}

A. Kesimpulan
Berdasarkan hasil evaluasi kualitas website Sistem Informasi Akademik (SIAKAD) menggunakan metode McCall dapat disimpulkan beberapa hal sebagai berikut :

1. Dari faktor kualitas Correctness SIAKAD direpresentasikan cukup baik. Rekomendasi yang dapat diberikan untuk perbaikan atas kualitas kebenaran yakni pada peningkatan kualitas informasi yang dibutuhkan yang selalu terbaru, hal ini diperlukan agar pengguna mendapatkan informasi terbaru dan tidak merasa bosan dengan informasi yang tidak berubah-ubah.

2. Dari faktor kualitas Reliability memiliki interpretasi baik. Rekomendasi yang dapat perlu untuk dilakukan perbaikan terhadap kemampuan website SIAKAD dalam melakukan pelayanan kepada pengguna, usulan perbaikan terhadap fungsi - fungsi dari menu SIAKAD, hal ini dilakukan secara rutin agar error yang terjadi selalu dalam monitoring UPT TIK dengan harapan meningkatkan kinerja SIAKAD yang handal.

3. Dari faktor kualitas Efficiency SIAKAD direpresentasikan baik. Rekomendasi yang dapat diberikan kepada pengembang website SIAKAD yakni mempertahankan kinerja saat ini atas sumberdaya yang telah dimiliki. Performa SIAKAD yang baik memberikan kenyamanan kepada pengguna SIAKAD.

4. Dari faktor kualitas Integrity SIAKAD direpresentasikan baik, SIAKAD bebas dari ancaman malwarem blacklisting, Injected SPAM dan Defacements. Namun untuk usulan kepada pengembang website SIAKAD yakni membutuhkan pihak ketiga dalam pemasangan firewall di SIAKAD.

5. Dari faktor kualitas Usability SIAKAD direpresentasikan hasil cukup baik. Adapun rekomendasi yang terbaik untuk perbaikan SIAKAD dari sisi Usablity yakni pada fasilitas pesan kesalahan, perlu ditingkatkan sehingga pengguna tidak bingung apabila mendapatkan permasalahan seperti Bukti Registrasi yang tidak muncul karena mahasiswa salah dalam mengetikan tahun akademik. Diharapkan ada pesan untuk memasukan data yang benar sehingga pengguna tidak bingung untuk memasukan data pada informasi yang pengguna butuhkan.

B. Saran

Saran untuk pengembangan penelitian ini selanjutnya yakni :

1. Evaluasi kualitas software dengan dilengkapi dengan pengujian kualitas berdasarkan product 
transition dan Product Revision, hal ini membuat penelitian kualitas website menjadi lengkap.

2. Perlu di lakukan uji kualitas pelayanan SIAKAD, selain Kualitas Website SIAKAD. Dengan ini pengguna lebih berminat untuk selalu menggunakan SIAKAD.

3. Diperlukan dilakukan proses tata kelola terhadap SIAKAD menggunakan framework Cobit untuk mengetahui tingkat kematangan dari SIAKAD.

\section{Referensi}

[1] Monalisa, Siti. "Analisis Kualitas Layanan Website Terhadap Kepuasan Mahasiswa dengan Penerapan Metode Webqual (Studi Kasus: UIN Suska Riau)." Jurnal Sains, Teknologi dan Industri 13.2 (2016): 181-189.

[2] Hutahaean, Jeperson. Konsep sistem informasi. Deepublish, 2015.

[3] Anwariningsih, Sri Huning. "Multi Faktor Kualitas Website." Gaung Informatika 4.1 (2011).

[4] Napitupulu, Darmawan Baginda. "Evaluasi kualitas website universitas XYZ dengan pendekatan webqual [Evaluation of XYZ university website quality based on Webqual approach]." Buletin Pos dan Telekomunikasi 14.1 (2016): 51-64.]

[5] Andria, Andria, Kusrini Kusrini, and Armadyah Amborowati. "Evaluasi Kualitas Web Portal STT Dharma Iswara Madiun Menggunakan Metode McCall." Jurnal Ekonomi Dan Teknik Informatika 4.2 (2017): 33-43.

[6] Jogiyanto, H. M. (2017). Analisis dan Desain (Sistem Informasi Pendekatan Terstruktur Teori dan Praktek Aplikasi Bisnis). Penerbit Andi

[7] Khairullah, Khairullah, Bambang Soedijono, and Hanif Al Fatta. "Pengukuran Kualitas Sistem Informasi Inventaris Aset Universitas Muhammadiyah Bengkulu Menggunakan Metode MCCALL." Informasi Interaktif 2.2 (2017): 84-92.

[8] YUDHANARSI, RINI (2010) Sistem Informasi Akademik Berbasis Multi User Pada Universitas Boyolali. Other thesis, STMIK Sinar Nusantara Surakarta.

[9] Rafa E. Al-Qutaish, "Quality Models in Software Engineering Literature: An Analytical and Comparative Study

[10] Indrajit, Richardus Eko. "Kriteria Penjamin Kualitas Perangkat Lunak." vol 6 (2012): 1-6. 